Artículo de reflexión

Cuestiones de filosofía

ISSN: 0123-5095

Vol. 2 - No. 19

Julio - dciembre, año 2016

pp. 53-65

\title{
EI lenguaje poético como experiencia de la verdad Lecturas gadameriana y romántica*
}

\author{
Poetic language as an experience of truth. \\ Gadamerian and romantic readings
}

\section{Carlos Andrés Gallego-Arroyave** \\ Fundación Universitaria Luis Amigó}

Colombia

Fecha de recepción: 2 de julio del 2016

Fecha de evaluación: 15 de septiembre del 2016

Fecha de aceptación: 1 de octubre del 2016

* Esta investigación se llevó a cabo dentro de las dinámicas del semillero de investigación Estética, poética y hermenéutica que se encuentra inserto en el grupo de investigación Filosofía y teología crítica de la Fundación Universitaria Luis Amigó (Medellín). Colombia.

** Estudiante de Filosofía de la Fundación Universitaria Luis Amigó (Medellín). Miembro del Grupo de Investigación Filosofía y Teología Crítica. Categoría C. carlos.gallegoar@gmail.com 


\title{
Resumen
}

El lenguaje poético tiene una valoración importante dentro de la hermenéutica gadameriana y el temprano romanticismo alemán, dado que les proporciona a estas dos corrientes comprensión, revelación y experiencia de la verdad más real, brindando, además, una constitución y un incremento ontológico que unifique el dualismo separado por la modernidad: hombre-mundo. Por lo tanto, este artículo de reflexión analiza fundamentos estéticos y filosóficos que den pie para hallar una correspondencia entre Gadamer y los románticos, y, a partir de esta correlación, indagar si el arte, y propiamente el lenguaje poético, causa una nueva representación y comprensión de la realidad y una autocomprensión del propio hombre.

Palabras clave: Arte, Hermenéutica, Lenguaje, Poesía, Romanticismo alemán.

\begin{abstract}
Poetic language has an important value for Gadamer's hermeneutics and for the early German Romanticism, because it allows these two currents a sense of comprehension, disclosure and experience of the realest of truths, providing a constitution and ontological growth as well, which unifies the Modern dualism between man and world. Therefore, this reflection article analyses some of the aesthetical and philosophical foundations which make a connection between Gadamer and the romantic authors possible. Drawing from this correlation, an inquiry about the role of art and poetic language in the creation and comprehension of reality and man himself is made.
\end{abstract}

Keywords: Art, German romanticism, Hermeneutic, Language, Poetry.

\section{LA OBRA DE ARTE DENTRO DE LA HERMENÉUTICA GADAMERIANA}

Es necesario decir que la idea del arte como lenguaje no es una categoría filosófica moderna o contemporánea, pues viene presentándose desde la Grecia antigua, con el término mimesis, que bien puede darse desde la vertiente platónica o el arte poético aristotélico (Domínguez Hernández, 2003, p. 104); sin embargo, esta primera idea del arte como lenguaje ha sido rehusada por una más racionalista y científica, llevándola, esencialmente, a un campo metódico, positivista y 
antimetafísico. El profesor Domínguez Hernández expone de modo más aclaratorio cómo la filosofía del lenguaje ha convertido la estética en una manifestación metódica:

En los últimos años se ha dado una discusión sobre la analogía entre el lenguaje y el arte, de una amplitud tal que hoy resulta inabarcable. En dicha discusión predominó el esfuerzo por ganar claridad metódica en la interpretación que llevan a cabo las ciencias del arte, y para ello se hizo uso de las ciencias del lenguaje, sobre todo de la lingüística estructural (2003, p. 104).

La orientación científica y estructural del arte como lenguaje no será expuesta en este trabajo; la directriz que tomará es la teoría hermenéutica de Hans-Georg Gadamer, que inserta y aprehende características griegas, idealistas, románticas y fenomenológicas con el fin de aclarar "de entrada su constante y profunda confrontación con las obras de arte, sobre todo con las de la poesía” (Domínguez Hernández, 2003, p. 105).

La hermenéutica gadameriana aparece como agente de reacción ante el modo de pensar de las ciencias modernas, regidas por una racionalidad metódica, y se separa de la metafísica y el positivismo, que establecen un principio de razón suficiente que se aleja de las contradicciones. Por lo tanto, la verdad que sostendrá la hermenéutica filosófica es donde el ser se comprende, es decir, acontece al ser del hombre, que se da por medio del lenguaje que debe concretarse, posteriormente, a la experiencia. El lenguaje, entonces, como experiencia hermenéutica, proporciona una concreción del mundo en sentido histórico, que, en consecuencia, le da al hombre un despliegue de experiencias en ese propio mundo ${ }^{1}$. Para Gadamer es de especial interés la experiencia que se comprende en el arte, dado que: "La presencia de las obras de arte media toda distancia y nos hace encontrar con nosotros mismos, pues en la experiencia del arte el espíritu encuentra al espíritu, el hombre vuelve a sí mismo, enfrentado momentáneamente con el todo que templa

1 Para Gadamer, la "experiencia" dentro de la hermenéutica es el epicentro o núcleo para la constitución ontológica del propio método; por lo tanto, la "experiencia" hermenéutica es propiamente lenguaje (diálogo) que tiene la posibilidad de construir la comprensión histórica tanto del lenguaje como del individuo. En este orden, Pablo RodríguezGrandjean sostiene que el "lenguaje es experiencia del mundo" (2002, p. 4), es decir, la "experiencia" es característica fundamental para conocer algo, pero no sedetiene en ese 'saber algo', sino que manifiesta "un descubrir cada vez facetas nuevas en un proceso que nunca es ni puede considerarse definitivo" (2002, p. 5). 
su existencia" (2003, p. 106). Esta cita confirma que el lenguaje del arte, fundamental el de la poesía, hace que sea posible la comunicación, el diálogo vivo entre hombre y mundo, que el primero haga parte del segundo, y que este tome una singularidad para la comprensión y percepción del hombre.

Para que la experiencia del arte sea experiencia de lo real y verdadero se debe, antes que nada, contemplar la justificación que da Gadamer de arte. La hermenéutica filosófica anula por completo lo que se denomina "conciencia estética" o, como afirmaría Grondin (2009), la destrucción de la estética. La renuncia que hace la hermenéutica de la "conciencia estética" sucede porque esta manifestación moderna de concebir el arte está privando la pretensión de verdad del propio arte; hay una supresión de un enunciado real que transmite la obra artística. La discusión que realiza Gadamer en las primeras páginas de Verdad y Método (2003) debe sustentarse a partir de la fundamentación kantiana de la estética, poniendo especial atención en dos asuntos: primero, la relevancia moral y política que estaba incursionada en el juicio estético que, luego, va refiriéndose a un modelo epistemológico y de validez (2005, pp. 61-66) ${ }^{2}$; segundo, hace hincapié en la universalidad subjetiva del juicio del gusto ${ }^{3}$, es decir, que esta universalidad se da por el "juego de facultades de conocimiento que evocan un juicio estético" (2009, p. 58). Gadamer describe este segundo aspecto de la fundamentación estética kantiana de la siguiente manera:

Sin embargo, el interés esencial de Kant era lograr una fundamentación de la estética autónoma y libre del baremo del concepto; no plantear la cuestión de la verdad en el ámbito del arte, sino fundamentar el juicio estético en el

2 Kant, en la Primera introducción a la Crítica del Juicio (1987), sustenta en el tercer apartado que el Juicio es la "capacidad de subsumir lo particular en lo general" (p. 31). Por lo tanto, el Juicio es la facultad que está en medio del entendimiento y la razón (razón pura y razón práctica), dado que "El concepto de la libertad no determina nada referente al conocimiento teórico de la naturaleza; el concepto de la naturaleza, igualmente nada referente a las leyes prácticas de la libertad; en tal sentido, es, pues, imposible hacer un tránsito de una a otra esfera" (1991, p. 205), por lo que "el Juicio, proporciona el concepto intermediario entre los conceptos. de la naturaleza y el de la libertad, que hace posible el tránsito de la razón pura teórica a la razón pura práctica” (1991, p. 206)

3 En el parágrafo sexto de la Crítica del Juicio, que da inicio al segundo momento de la primera parte, Kant introduce de inmediato la universalidad de la representación de lo bello. Lo universal y la validez de lo bello se constituyen por medio del juicio libre y de satisfacción que se le da al objeto, por lo que, según Kant, la universalidad subjetiva del juicio estético es "una relación de la representación del objeto con el sujeto" (Kant, 1991, p. 215) 
a priori subjetivo del sentimiento vital, en la armonía de nuestra capacidad de "conocimiento en general" (2003, p. 95).

Esta querella que tuvo Gadamer con la Crítica del Juicio kantiana lo llevó a reformular la pregunta acerca de la experiencia del arte y a lograr un concepto más adecuado de este, proporcionando, además, una mejor adecuación y acontecimiento de lo verdadero. Por lo tanto, la obra de arte en Gadamer sobrepasará los límites de la subjetividad kantiana, dándole, por medio del lenguaje, una objetivación a la hermenéutica que señale la universalidad de la experiencia delmundo:

La función trascendental que asigna Kant a la capacidad de juicio estética puede ser suficiente para delimitarla frente al conocimiento conceptual y por lo tanto para determinar los fenómenos de lo bello y del arte. ¿Pero merece la pena reservar el concepto de la verdad para el conocimiento conceptual? ¿No es obligado reconocer igualmente que también la obra de arte posee verdad? (2003, p. 74).

La "conciencia estética", que estuvo imperando dentro de la modernidad y que tomó fuerza en el siglo XIX gracias a las ciencias del espíritu, comenzó su decaimiento a causa de la reforma gadameriana, refiriendo que la obra de arte no debe considerarse como estética del genio o vivencia creativa que acarrearía una desaparición de la realidad dentro del propio arte. Ante esto, para que el arte sea un "arte vivencial", la hermenéutica utiliza la alegoría, que dentro de la propia obra no representará una experiencia estética, sino una experiencia de la realidad (2003, p. 114). Grondin aclara que la propia alegoría rechaza la separación entre arte y realidad, más bien rehabilita este vínculo que otorga la aparición de la esencia del arte: "El arte podrá sacarnos en gran medida de la cotidianidad, pero no puede situarse en oposición a la realidad y a nuestro conocimiento de la misma" (2009, p. 63). Por consiguiente, Gadamer comienza a hablar de arte como capacidad de representar, en toda significación, la realidad de la experiencia. En Verdady Método esta representación de la realidad será un proceso óntico, es decir, el arte como significación de lo real es manifestación de un "incremento del ser". Este proceso óntico es la adquisición de una autonomía del arte, proceso que se efectuó en la modernidad; pero esta autonomía no debe pertenecer a lo imaginario o irreal, sino que corresponderá con lo real (2003, p. 193). Esta explicación ontológica desarrollada por Gadamer se hace patente por medio de un concepto que Kant y Schiller habían utilizado desde la significación subjetiva: el juego. Esta imagen tiene 
para Gadamer el mismo funcionamiento que la experiencia del arte como "incremento del ser": poner como secundaria la subjetividad creativa y genial de la modernidad; no hay que darle la autonomía a lo subjetivo en el arte, pues el juego del arte es el que debe ser autónomo. El profesor Pedro Karczmarczyk expone la autonomía del arte a partir de la representación de juego:

El juego no se construye por un acto soberano de la conciencia de los jugadores, sino que estos se inscriben en el decurso temporal del juego, lo representan. Es decir, que al cumplir los roles del juego y las tareas que estos asignan, los jugadores hacen que el mismo juego esté presente una y otra vez, aunque siempre de maneras diferentes. Es el mismo juego jugado en diferentes ocasiones (2007, p. 162).

Esta propuesta de juego posibilita dos contemplaciones que obedezcan a la justificación de la experiencia del arte: primera, que la realidad expresada en el arte es autónoma y sobrepasa al hombre, sin embargo, este sigue implicado en ella (2003, p. 160); segunda, la objetividad y, continuamente, la subjetividad del arte, que, según Grondin, se ve mayormente lograda en la poesía (2009, p. 70). El juego es, por tanto, la representación y autorrepresentación del arte que se encamina hacia el "incremento del ser" (proceso ontológico) que brinda el conocimiento de la verdad y el vínculo entre hombre y juego del arte (Gadamer, 1991).

\section{El lenguaje PoÉtico como experiencia de Verdad. Gadamer y EL POSIBLe ACERCAMIENTO A LOS ROMÁNTICOS ALEMANES}

La experiencia de arte, la alegoría y el juego son figuras que Gadamer propone y sustenta para una reelaboración del concepto de arte, un "incremento del ser" en el propio arte y un acontecimiento de la verdad dentro del mismo para un reconocimiento del hombre, es decir, una anamnesis a través de la obra de arte: "El arte nos saca de nuestro olvido del mundo y nos abre los ojos para lo que es" (2009, p. 77). Pero para Gadamer no es el arte el que brinda la mimesis, sino el lenguaje que está inserto en todas las expresiones de verdad: "el lenguaje es, en efecto, para Gadamer, el ser de todo lo correspondido, el juego en el que todos jugamos, el reflejarse en sí del juego originario que constituye la esencia del movimiento de lo real" (Dottori, citado por Uña Juárez, 2008, pp. 89-90). Dado esto, es considerable presentar, dentro de la hermenéutica gadameriana, el arte como lenguaje. Gadamer lo manifestaría a partir de la siguiente pregunta: 
¿Es que realmente una obra de arte procedente de mundos de vida pasados o extraños y trasladada a nuestro mundo, formado históricamente, se convierte en mero objeto de un placer estético-histórico y no dice nada más de aquello que tenía originalmente que decir? Es en esta pregunta donde el tema "estética y hermenéutica" cobra la dimensión de su problematicidad más propia (Gadamer, 1998, p. 56).

El arte debe integrarse por completo a la hermenéutica. La experiencia del arte en Gadamer implica un comprender, esto es, un re-conocimiento, una mimesis, un expresar el mundo y una autocomprensión del hombre, si este comprende el arte. Domínguez Hernández (2003) lo expresa del siguiente modo: "[El arte como lenguaje] es la recuperación de una experiencia del arte en la que éste haga valer su verdad, lo que llamamos también su sentido o significado, y que no es otra cosa que la comprensión de su lenguaje" (pp. 113-114). Por lo tanto, el lenguaje en el que se logra un acontecimiento de la verdad y una comprensión en sentido hermenéutico es el poético, dado que, según Gadamer, "la lengua poética tiene una relación peculiar, muy propia, con la verdad" (1998, p. 111). El lenguaje poético, inserto en la experiencia del arte, es la forma de expresión más pura, es una dinamicidad que proporciona “transmisión, epifanía y revelación” (Uña Juárez, 2008, p. 94). Se nota que para Gadamer el lenguaje poético cumple algunas funciones esenciales para la hermenéutica filosófica, sin embargo, esta sección centrará su atención en la idea de verdad que pretenden establecer la poesía y el poeta, para dar credibilidad, veracidad e incremento al propio arte, que es el del lenguaje.

La esencialidad del lenguaje poético en Gadamer puede verse fundamentada, principalmente, por la poesía de Rilke y Stefan George ${ }^{4}$. Pero, si bien Gadamer

4 Rainer Maria Rilke fue para Gadamer el poeta por antonomasia de la nación alemana; aunque también percibió con gran valor la poesía georgeniana y hölderliniana, halló en la Elegías y los Sonetos una estética y didáctica en la poesía completamente constituida; tanto fue la perfección en la composición poética rilkeniana que Gadamer afirma que "Rainer Maria Rilke encontró su sonido constante y su final perduración sigue siendo verdad, como los otros mensajes de la literatura universal" (Gadamer, 2004, p. 35). Por su parte, Gadamer se acercó a la obra de Stefan George por el modo como este trató la poesía desde la juventud hasta la madurez de manera excelsa y real; puso la "voluntad poética" como eje esencial para hilar el espíritu de la época con los valores. La poesía y el lenguaje fueron para George manifestaciones de musicalidad que proporcionaron una verdad dentro de una experiencia viva. Geoge, según Gadamer, adujo que "sólo lo que esté confinado en la palabra, sólo visto y de todos visible está realmente presente" (Gadamer, 2004, p. 79). 
rechaza algunos postulados de la estética y el pensamiento filosófico alemán de los siglos XVIII y XIX, puede pensarse que también hubo un vínculo con la poesía y el pensamiento romántico, ya que en el Romanticismo hay un lugar preponderante del lenguaje poético como lugar donde acaece la experiencia del mundo. En las Acotaciones Hermenéuticas, Gadamer expone que cuando se habla de arte "nos situamos en un uso lingüístico que procede del Romanticismo alemán y que obtuvo en él su propia impronta" (2002, p. 183). El lenguaje poético dentro del Romanticismo tomó lo que para Gadamer sería un conocimiento de la realidad y un "decir algo": "este primer sentido de verdad [en la poesía] quiere decir, por tanto, que se dice lo verdadero, esto es, que se dice lo que se quiere decir" (Gadamer, 1998, p. 114).

Ante esto, en el pensamiento romántico temprano el lenguaje está atravesado por la reflexión filosófica y por la obra artística o literaria que posibilita lo que Novalis denominó, en sus Estudios sobre Fichte, "naturaleza mágica del lenguaje" (2010, p. 74); un lenguaje que devela la naturaleza del hombre y lo llama a revelar un mundo que se halla alejado de la exteriorización empírica. Es incuestionable la separación conceptual que hay entre Gadamer y los románticos; no obstante, hay un punto de encuentro entre ellos: la constitución de una experiencia de verdad en el arte. Esta experiencia de verdad, dada a través del lenguaje poético, tiene fundamento tanto en la hermenéutica filosófica como en el pensamiento de los tempranos románticos, puesto que ofrece la comprensión del hombre y su posición libre dentro del mundo, presentándose, además, como una acción de resistencia ante una escisión moderna del sujeto y el objeto, y, también, "ante un mundo desencantado, regido por la industrialización, en el que las cosas se diluyen en una existencia efímera" (Marzán Trujillo, 2002, p. 138). Dado esto, es posible que Gadamer hallara en la concepción de poesía dentro del Romanticismo un descubrimiento de la verdad revelada, y esta es esencialmente un "encuentro consigo mismo". Esto se afirma por el hecho de que el arte poético romántico constituye el discurso que salva al hombre moderno; Novalis lo sostiene en el siguiente fragmento: "La poesía cura las heridas que el entendimiento inflige" (2010, p. 169). Esta renovación de la poesía en el Romanticismo "como lengua universal del género humano" (Gadamer, 1998, p. 124) y como posibilitadora de unificación entre mundo y hombre, como categoría ontológica, también es palpable en la hermenéutica gadameriana, puesto que toda palabra poética expresa el mundo de sí mismo, y el hombre la comprende y avanza en su autocomprensión.

Si bien dentro del temprano Romanticismo alemán se halla cantidad de pensadores que brindan una reflexión de la poesía como elemento de representación y unificación 
entre "sujeto y objeto, alma y mundo" (Novalis, 1984, p. 106), este apartado centrará su atención en dos pensadores con consideraciones acerca del lenguaje poético que lograría un acercamiento al arte, según Gadamer; se hará referencia, entonces, a Novalis y Friedrich Schlegel. Un primer acercamiento que puede notarse entre románticos y Gadamer es la posición y exposición histórica de la poesía; por ejemplo, en Conversación sobre la poesía, de Schlegel, el primer discurso, el de Andrés, tiene como objetivo presentar cómo la literatura se transforma y se modifica a lo largo del tiempo por la individualidad del autor (2005, p. 40), por lo tanto, "El interés de Schlegel es concebir el desarrollo histórico de la literatura como la constitución de la literatura misma, mostrando qué es la poesía, qué puede llegar a ser y bajo qué formas se ha dado" (2005, p. 18). En Europa o la cristiandad, Novalis crea toda una exposición histórica donde poesía y mundo medieval se confluyen para crear un nuevo equilibrio de fuerza histórica, ya que la revaloración por medio de la poesía de un mundo pasado le permite al hombre reorganizar los acontecimientos de aquel pasado para entrever nuevos significados de esta época y una maduración del proceso de la humanidad:

Más encantadora y multicolor subsiste la poesía como una India adornada frente a las frías e inertes cimas del entendimiento de salón [...] [los poetas] fueron los primeros en entrever la santidad de la naturaleza, la infinitud del arte, la necesidad del conocimiento, la atención a lo mundano y la omnipresencia de la verdad en los acontecimientos históricos (Novalis, 2009, p. 44).

Quizás estas contemplaciones históricas de la poesía y el hombre en el pensamiento romántico no están absolutamente aprehendidas a la hermenéutica gadameriana, sin embargo, puede obtenerse alguna correspondencia. Si bien la obra de arte -o la poesía-tiene para Gadamer un "presente intemporal", no puede fijarse la palabra poética sin un origen histórico, es decir, la obra de arte tiene su propio presente y es intemporal; pero para que haya un vínculo con el hombre y una comprensión en sentido hermenéutico debe mantener y encontrar el origen histórico: "En este sentido, la obra de arte es de un presente intemporal. Pero ello no quiere decir que no plantee una tarea de comprensión y que no haya que encontrar también su origen histórico" (Gadamer, 1998, p. 56). Este elemento de lo histórico dentro del arte, según Gadamer, da la concesión de que el lenguaje poético equivalga a tener un mundo, a representar la realidad, una verdad que sin duda nos dirá algo, tomará una representación ontológica que propicie corporeizar a través de la poesía imágenes de la experiencia y de la comprensión humana: "La obra de arte le dice algo a uno, y ello no sólo del modo en que un documento histórico le dice algo al 
historiador: ella le dice algo a cada uno, como si se lo dijera expresamente a él como algo presente y simultáneo. Se plantea así la tarea de entender el sentido de lo que dice y hacérselo comprensible a sí y a los otros" (Gadamer, 1998, p. 59).

Lo ontológico dentro del lenguaje poético de Novalis y Schlegel también toma una posición relevante, ya que el discurso analítico mantiene unas insuficiencias que la poesía romántica está llamada a superar a partir de las correspondencias de dos acepciones: "la literaria, por un lado, y la filosófica, en su doble versión metafísica y utópica por otro" (Novalis, 2010, p. 170). De este modo, en su fragmento Sobre el poeta y la poesía, Novalis considera que "la poesía es la realidad absoluta [...]. Cuanto más poético, más verdadero. El artista se levanta sobre el hombre como la estatua sobre el pedestal" (1984, p. 105). Con Schlegel se nota que la poesía romántica no solo pretende unificar los géneros poéticos para una creación más solemne del pensamiento romántico, sino que aquella también accede al conocimiento de la realidad y la verdad a partir del punto de vista de la obra. Esta verdad, distinta a la experiencia de verdad gadameriana, que está inserta en la poesía es revelación de lo absoluto, establece una experiencia estética como mediación entre hombre y mundo. En el fragmento 16 de la revista Athenaeum aparece la manifestación ontológica de la poesía romántica y el acceso a la realidad del mundo:

La poesía romántica es una poesía universal progresiva [...]. Pretende y debe mezclar y fundir poesía y prosa, generalidad y crítica, poesía artística y poesía natural; por una parte, debe hacer más viva y social la poesía, y por otra la vida y la sociedad más poéticas [...]. Sólo la poesía romántica puede ser, al igual que la epopeya, un espejo de todo el mundo circundante, un cuadro de la época $(1983$, p. 130).

La palabra o el lenguaje poético en Gadamer y los románticos, a través del carácter histórico, ontológico y de verdad, trasciende del lenguaje habitual hacia la creación de un mundo nuevo donde la propia palabra tome una "fuerza realizativa" y de experiencia. En este nuevo mundo, el arte como lenguaje, o propiamente la palabra poética, "se sustenta a sí mismo, en el que también se inscribe una pretensión de verdad [...]. Un mundo, en suma, que se erige como un enigma cuya interpretación deviene inagotable (Marzán Trujillo, 2002, p. 142). La poesía, más que acto lingüístico, es propiedad ontológica y hace emerger un orden nuevo del ser mismo del arte y, además, surge una realidad que pretende ser tan real como lo plasma la palabra común. Tal vez sea en Novalis y sus Himnos a la noche donde se efectúa esa máxima del poeta: “cuanto más poético, más verdadero", dado que, en los 
Himnos, con la concepción místico-poético que se halla allí, se encuentra también una expresión y recreación de ese nuevo mundo que podría ser la "noche sagrada y eterna" donde se da una mismidad entre poesía y verdad. Y sea el Himno VI la exteriorización de esa verdad, porque en este mismo himno la poesía permite el surgimiento de una realidad que, si bien excede la propia naturaleza de lo real, tiene la consideración de verdad que facilita la revelación de lo absoluto:

Loada seas, noche eterna,

Loado, sueño eterno.

Nos abrasó el calor del día, nos marchitó la larga cuita.

Ya el deseo de extrañas tierras

se ha desprendido de nosotros:

volvamos al padre, al hogar (Novalis, 2001, p. 38).

Por otro lado, la palabra poética dentro de la hermenéutica filosófica siempre intenta trascender por medio del lenguaje para la constitución de un mundo. La poesía, como elemento para la búsqueda de la verdad, no solo debe acabarse con el "decir algo", sino que el enunciar algo a través de la poesía facilita que el hombre aspire a nuevas experiencias y horizontes más amplios y ricos (Gadamer, 1998, p. 112). "La palabra poética es tal que resulta única e inintercambiable" (Gadamer, 1998, p. 113); esto implica que la poesía sobrepasa el lenguaje cotidiano y se asienta sobre sí misma, y ese estar "ahî" de la poesía da oportunidad de crear mundos y de que el propio lenguaje poético, a partir de la búsqueda de la verdad, incremente y restaure su ser, demostrando que "el lenguaje poético no es una simple elevación y afinamiento del lenguaje usual" (Gadamer, 2002, p. 142). Lo sobresaliente, entonces, de lo que se denomina verdad o verdadero dentro de la palabra poética es lo que hay detrás de lo está escrito o pronunciado, de lo que se quiere decir. Ante esto, Gadamer certifica que lo verdadero en lo poético está en la "declaración" (Aussage). Esta "declaración” permite que lo que hay detrás del poema quede respondido por este mismo para, después, acontecer lo verdadero ("poema efectivamente verdadero") por medio de una "experiencia de cercanía" de la poesía. Esta es la instalación de un espejo que no refleja el mundo como realidad, sino "la intimidad misma en la que nos estamos un rato" (Gadamer, 1998, p. 119). Aun cuando la poesía no es reflejo dentro mundo, Gadamer sostiene que la poesía como lenguaje o acto lingüístico da un acceso al mundo y experiencias del hombre, confirmando, entonces, que la palabra nos atestigua nuestra existencia ahí en tanto que ella misma es existencia ahí (1998, p. 121). 


\section{CONSIDERACIONES FINALES}

Quisiera finalizar reiterando que no hay con absoluta certeza una relectura o reinterpretación hecha por Gadamer de los románticos alemanes; simplemente se brindaron unos cuantos puntos de encuentro entre estos pensamientos, y a pesar de que ambos proceden o reflexionan de modo asistemático, es claro que existen distanciamientos al momento de tratar el lenguaje, la poesía y el descubrimiento de lo verdadero, o absoluto, para la relación hombre-mundo. En síntesis, se recogieron elementos de la estética hermenéutica (juego, alegoría, experiencia, comprensión, etc.) para una mejor clarificación de la interpretación hecha por Gadamer para una nueva reflexión y visión de lo que sería el arte para el hombre del siglo xx, que le proporcionaría, a través del lenguaje poético, una autocomprensión y experiencias de y con la realidad. Dada esta interpretación reformadora gadameriana, se intentaron fijar unos enlaces con una apreciación del arte en los siglos XVIII y XIX dentro del movimiento romántico, que también transformó la manera como se presenciaba y estudiaba el arte, esto con el fin de develar y revelar un absoluto que permitiese la unificación del hombre con el mundo. Por lo tanto, es pertinente decir, a modo de conclusión, que con el desarrollo de los elementos históricos, ontológicos y de verdad entre la hermenéutica filosófica y el Romanticismo alemán, el lenguaje poético, como principio importante para ambas corrientes, otorga y produce una experiencia de verdad para la unificación y comprensión de lo que antes estaba escindido y oculto: hombre y realidad.

\section{REFERENCIAS}

Domínguez Hernández, J. (2003). El arte como lenguaje. En J. Domínguez Hernández, Cultura del juicio y experiencia del arte. Ensayos. (págs. 104-126). Medellín: Universidad de Antioquia.

Gadamer, H.-G. (1991). La actualidad de lo bello. Barcelona: Paidós.

Gadamer, H.-G. (1998). Estética y hermenéutica. Madrid: Tecnos.

Gadamer, H.-G. (2002). Transformaciones en el concepto de arte. En H.-G. Gadamer, Acotaciones hermenéuticas (págs. 181-198). Madrid: Trotta.

Gadamer, H.-G. (2003). Verdad y Método I. Salamanca: Sígueme.

Gadamer, H.-G. (2004). Poema y diálogo. Barcelona: Gedisa. 
Grondin, J. (2009). Introducción a Gadamer. Barcelona: Herder.

Kant, I. (1987). Primera introducción a la "Crítica del Juicio”. Madrid: Visor.

Kant, I. (1991). Crítica del Juicio. México D. F.: Porrúa.

Karczmarczyk, P. (2007). La subjetivación de la estética y el valor cognitivo del arte. Según Gadamer. Analogía filosófica, 127-173.

Marzán Trujillo, C. (2002). El significado de la poesía en la hermenéutica filosófica. Revista Laguna, 137-151.

Novalis. (1984). Escritos escogidos. Madrid: Visor.

Novalis. (2001). Himnos a la noches y Cánticos espirituales. Valencia: PreTextos.

Novalis. (2009). Europa o de la cristiandad. México D. F.: UNAM.

Rodríguez-Grandjean, P. (2002). Experiencia, tradición, historicidad en Gadamer. A Parte Rei: revista de filosofía, 3-21.

Schlegel, F. (1983). Fragmentos. Madrid: Fundación Universitaria Española.

Schlegel, F. (2005). Conversación sobre la poesía. Buenos Aires: Biblos.

Uña Juárez, O. (2008). Comunicación y lenguaje poético. El caso de Gadamer. Revista Española de Sociología, 87-106. 